\title{
Development of Biomass Power Generation in China: Constraints and Measures for Perfection
}

\author{
Yuechen Hao ${ }^{1} \&$ Guoliang Luo $^{2}$ \\ ${ }^{1}$ School of Electrical and Electronic Engineering, North China Electric Power University, China \\ ${ }^{2}$ School of Economics and Management, North China Electric Power University, China \\ Correspondence: Guoliang Luo, School of Economics and Management, North China Electric Power University, \\ China. E-mail: lg11965@126.com
}

Received: August 29, 2012 Accepted: September 21, 2012 Online Published: November 30, 2012

doi:10.5539/ass.v8n15p238

URL: http://dx.doi.org/10.5539/ass.v8n15p238

\begin{abstract}
Having started late in China, the development of biomass power generation currently encounters many restraining factors, such as the inconclusive biomass resources distribution, the obstructed supply channel of raw materials, the weak foundation of technology industrialization, the immature market mechanism, imperfect relevant laws and regulations, as well as unfriendly market environment. By reviewing the development of biomass power generation industry in foreign countries and analyzing China's present conditions, this paper puts forward some counter measure for the orderly development of China's biomass power generation.
\end{abstract}

Key words: biomass power generation, generation cost, $\mathrm{R} \& \mathrm{D}$, financing channels

\section{The Current Development of Biomass Power Generation Industry in China}

\subsection{Continuous Expansion of Biomass Power Generation in China}

The raw material for biomass power generation is mainly agricultural wastes, forestry waste, and industrial waste, which are directly burned or gasified for power generation. The Renewable Energy Law of China issued in 2005 stipulates that "the Government encourages and supports the integration of biomass power into the grid", and its promulgation and implementation provides the legal guarantee and lays the foundation for biomass power generation in China. With the related supporting laws, regulations, and polices for implementation of the law being published in succession, China's biomass power generation has enjoyed an unprecedented growth. By the end of 2005, China's overall biomass power generating capacity amounted to $2000 \mathrm{MW}$, of which the power generation using crane wastes took up a larger part, and the rest was generated through gasification of rice hulls. Since 2005, three power generation demonstration projects based on straw have been completed, and the straw power generation witnessed a rapid development. Meanwhile, the construction of refuse incineration power plants has been accelerated.

By the end of 2009, some 170 biomass generation projects have been approved by the National Development and Reform Commission (NDRC), totaling 4,600 MW of generating capacity. Fifty projects have been put into operation, totaling 1,110 MW. By the end of 2010, the total generating capacity of biomass power reached 5,550 MW. The production capacity of China's biomass power generation continues to grow.

\subsection{Biomass Power Generation Enterprises as Large-scale Business Operation Model}

With the continuous expansion of the industry, biomass power generation enterprises have been undertaking a transition to large-scale business operation model. Established in 2005, National Bio-energy Group has become the world's largest professional company integrating business investment, construction, and operation of biomass power generation projects. The company has nearly 50 biomass power plants in Shandong, Hebei, Henan, Jiangsu, Heilongjiang, Jilin, Inner Mongolia, Xinjiang, Hubei, and Shaanxi, with a total of 10 billion Yuan of investment and annual revenue of 3 billion Yuan. Eighty percent of refuse incineration power plants of the company were built in the last five years. Leading businesses for the related technology development, manufacture of the power generators, investment, and logistics service have been consolidated within the group. 


\subsection{Wide Distribution of Biomass Power Generation Projects}

Biomass power generation plants using crop straw are mainly concentrated in agricultural areas. By the end of 2006, there had been 34 crop straw power generation projects under construction across the country with a total of 1,200 MW of generating capacity. By the end of 2010, Shandong province had put into operation 27 biomass generation plants totaling $642 \mathrm{MW}$ of generating capacity, which provided 1.3 billion KWh of green energy.

Although starting late in China, the refuse incineration power generation has grown very fast in recent years. The refuse incineration power projects are mainly located in the coastal areas and a few inland cities. Since Shenzhen Municipal Environmental Sanitation Comprehensive Treatment Plant, China's first refuse incineration power generation plant, was completed in 1988, nearly 30 similar plants have been built in large cities such as Shanghai, Tianjin, and Harbin in the Eleven Five-year. In 2010, there were 41 refuse incineration power projects proposed to be built in 16 provinces, municipalities, four projects in are located in Hebei; three in Tianjin and Fujian, respectively; two in Chongqing, Sichuan, Jiangxi, Hubei and Guangxi, respectively; one in Shanxi, Zhejiang, Anhui, Henan, Hunan, Hainan and Shaanxi, respectively. Guangdong has the most with 14 projects under planning.

\subsection{Continuous Increase in Policy Support for Biomass Power Generation}

The Chinese government attaches great importance to the biomass power generation industry. Since the Renewable Energy Law was enacted on Jan. 1, 2006, the administrative regulations and rules related to the implementation of the law have been issued in succession. In September 2006, the Ministry of Finance, the National Development and Reform Commission, the Ministry of Agriculture, and State Taxation Administration and the State Forestry Bureau jointly issued "Decisions on Implementation of Financial and Tax Support Policy for the Development of Biomass Energy and Biochemical Industry, defining the specific support polices for the development of biomass energy and biochemical industry. To promote the steady development of the biomass energy industry, the Ministry of Finance issued Provisional Methods on Special Funds for Biomass Energy Development (the Methods) on Oct 4th, 2006, providing the detailed and comprehensive regulations of the key support, application and approval, financial management, and assessment and supervision of the special funds. According to the Methods, the special development funds shall be established by the financial departments of the State Council in accordance with the law and utilized by means of free sponsorship and discount loans and arranged in the budget of the central government.

In 2007, a rudimentary regime of fiscal and tax support for new energy development was established, including the management measure for utilization of the special fund for renewable energy development, and the implementation guideline of the fiscal and tax support policies for biomass energy and biochemical industry development.

With the further implementation of China's biomass energy development strategies, the policy support on biomass power generation has also been intensified accordingly. On July 23rd 2010, the NDRC issued Notice on Improvement of Agriculture and Forestry Biomass Power Price Policy, uniformly raising the online price of the biomass power price to 0.75 Yuan per KWh (including tax). In the garbage power policy, it is stipulated in the Enterprise Income Tax of the PRC that the government shall guarantee that the power grid provides access to the grid all the power generated out of garbage, and grand 0.25 Yuan per KWh as subsidy. Garbage power shall be exempt from the value-added tax. The enterprise income tax shall also be exempt for the first three years, and reduced by $50 \%$ discount income tax for the next three years. Meanwhile, the local government shall provide garbage handling subsidies.

As the biomass energy industry is closely related to the construction of the New Countryside, since the end of 2010, the Ministry of Finance, the Ministry of Agriculture and the State Energy Bureau, and other departments of the central governments have jointly promoted the project of Green Energy Demonstration Counties (GEDC). It is planned that in the Twelfth Five-year, 200 GEDCs will be established and the central government will provide 4.75 billion Yuan in the form of direct subsidies. As many as 108 counties have become the first batch of GEDCs. In 2011, the NDRC sponsored preparation of the implementation plan for comprehensive utilization of crop straws and issued the pilot work plan in order to effectively address the supply of the raw materials for biomass power generation in some areas.

\section{Constraints in China's Biomass Energy Development}

\subsection{Lack of Systematic and Scientific Overall Planning}

Although the governments at all levels and the whole society lay great emphasis on the biomass energy industry, and a series of measures and actions have been taken and positive achievements have been made in this aspect. 
Nevertheless, there is a general lack of comprehensive and in-depth investigation and analysis with regard to the basic information on the distribution and development potential of biomass resources.

Whether in the development coordination between biomass energy and other renewable energies, or in the internal structure of the biomass energy industry, the central government and local governments at all levels have not been well prepared with overall, systematic and in-depth research and scientific planning, leading to somewhat disorderly development of the garbage and crop straw power generation in some areas.

\subsection{Independent Technology Research and Development Ability for Biomass Power Generation}

The industrialization of biomass power generation technology is still emerging in China, and the independent technology research and development is largely insufficient and immature, leading to a lack of the core technology of independent intellectual property rights and technical standard system. Since we are rather weak in equipment manufacture of biomass power generation, there is a heavy reliance on foreign suppliers in terms of the technology and equipment manufacture; a wide gap of both technology and production between China and advanced countries have therefore been formed. The technology and equipment of the biomass power generation, including the harvesting, packaging, transportation, storage, fuel adaptability for combustion equipment, pre-treated feeding, combustion control and ash handling, particularly in the direct combustion boiler design technology and equipment manufacture, have still been monopolized by a few foreign companies. On the contrary, without independent core technology, China has been only been experimenting the manufacture of the biomass power generation boiler at present. As a result, both technology and equipment need to be imported, and the independent research and development is scarce and in low quality.

\subsection{The High Cost of Biomass Power Generation}

Nearly all the elements involved in biomass power generation mechanism suffer from the high cost, including raw materials, logistics service, equipment as calculated per unit of power generating capacity, maintenance of the grid-connecting device, and the overall operation of the plant. For instance, when it comes to straw power generation, with maintenance cost of vehicles and fuel and manpower consumption considered, the economical purchasing radius should be less than 50 kilometers. However, due to a lack of professional logistics operators, the biomass power plant has to purchase raw materials either at a designated place or directly from scattered farmers. There is simply no scale benefit in the acquisition of raw materials, therefore increasing purchasing cost For example, the predicted price of straw delivered to the plant in a feasibility study of a certain biomass power generation project was around 150 Yuan per ton, but the finalized purchase price in the field reached as high as 150 Yuan per ton. In addition, the processing cost of raw materials (including the cost of cutting and packing and equipment depreciation), the cost of storage and transportation, the loss account for a large share of the fuel cost, as well as the cost of labor, the final price of straw fed into the boiler could reach as high as 300 Yuan, which is neither practical or affordable to promote biomass power generation nationwide. Furthermore, compared with conventional power plants, the generating capacity of biomass power plant is smaller, yet additional facilities are required, especially special storage fuel collecting and storage facilities. Moreover, power plants are responsible for power transformation and transmission onto the grid. The aforementioned factors contributed to high investment and construction cost per $\mathrm{KW}$ and higher operation cost for the biomass project. The cost per $\mathrm{KW}$ generating capacity in Suqian, Weixian, and Jinzhou biomass power plants all reach 10,000 Yuan, which is almost two times as much as the cost of a conventional coal-fired plant.

\subsection{The Relevant Law and Government Support Policy}

Despite the Renewable Law issued by the Chinese government, the specialized and detailed rules and regulations for biomass energy industry have yet to be fine-tuned. Appropriate, coordinated, and effective incentive policies in terms of the fiscal, financing, price, industry and market access are not available at present. The related management system is also guilty of excessive or inappropriate incentives, resulting to uncoordinated industry development drive and disorderly industry development. The regulatory system of the industry mainly focuses on the market access and the price control. At present, the market access of the biomass energy industry mainly functions the approval and issuance of the permit for an enterprise specializing in the production and sales of biomass energy; the price control targets on the pricing system of biomass power generation. In the aspect of the market access, some entities actually build and run small-sized coal-fired plants under the guise of constructing refuse incineration power plants or straw power plants, which leads the biomass power industry to go astray. Meanwhile, while the current inflexible pricing system for biomass energy (the average power generation price of all the biomass power generating units, plus a fixed price of subsidy) fails to reflect the gaps and time difference among regions in China. In addition, fixed subsidies for biomass power generation proved are too little to cover a substantial part of the cost of the biomass power generators. Finally, the industry has an 
overreliance on the government policy with little initiative to seize market, which is counterproductive to maximally reduce the biomass energy price, to optimizing the structure of power resources and power projects, or to giving rise to low efficiency in the resource allocation.

In addition, the present policies on biomass energy are considerably uncoordinated. The policy regarding the biomass power price and cost sharing is formulated by the NDRC, whereas the related fiscal and tax policies are issued by the Ministry of Finance and State Taxation Bureau. The Ministry of Agriculture makes decisions on the production area and production planning of raw materials of crop straws, while the environmental protection and construction management departments are responsible for garbage disposal and construction planning. Insufficient coordination between the regulatory and fiscal policies restricts the development of biomass power generation industry.

\subsection{Single Investment and Financing Channel and Unsound Market Mechanism}

Biomass power generation is an emerging industry, of which the technology development and market cultivation demands a large amount of capital investment. Currently, while there lacks the investment and financing channel, the market operation mechanism is also incomplete.

The maturing market mechanism gives rise to insufficient input of investment and R \& D from the investors and production entities in both domestic and foreign markets, as well as the excessive development in certain aspects. In recent years, the biomass power generation industry in some areas has grown overly fast. Actually, the seasonal and scattered agricultural production is unlikely to constantly feed the continuous and concentrated the biomass power generation, Unfortunately, enterprises tend to produce in accordance with the economical scale, therefore some biomass power plants have to expand the raw materials collection radius to $100 \mathrm{~km}$ or even 200 $\mathrm{km}$. Ultimately the difficulties of raw material supply negatively affect the operation of the biomass power plants.

\subsection{Insufficient Supporting Mechanism}

With the growing emphasis on biomass energy industry and the increasing requirement of scientific development, the existing government regulation mechanism, the business operation and management mechanism, and the customer consumption mechanism obviously fail to meet the needs of the current market, waiting to be strengthened and improved.

In the biomass power generation industry, there is little guarantee for raw materials supply and logistics services, or the quantity and quality of the raw materials. Different from those large farms in developed countries, China's farming units are rather small and the biomass materials are scattered. Fierce competition for the raw materials from other sectors (i.e., agriculture, animal husbandry, paper manufacture, and furniture and building materials manufacture) and a lack of specialized logistics enterprises in this specific field often creates difficulties in the supply of the raw materials for the biomass power plant. Even worse, some farmers focus merely on self-interest, mixing water, sand, and other substance in the crop raw materials. The inferior quality of the raw materials severely affects the smooth operation of the power generating facilities.

From the above analysis, while the biomass energy development in China has already begun to take shape, many restrictive factors still exist in the overall development planning, policy support system, research and development route, investment and financing system, market mechanism, and other supporting management systems. Therefore, we need to learn from the rewarding development experience from other countries.

\section{Biomass Power Generation Industry Development in Advanced Countries}

\subsection{Development Planning and Strategies}

In the USA, Japan, Brazil, and other countries, the appropriate strategic planning for biomass energy industry is decided based on the endorsement of the biomass resources in the country. Based on this strategic planning, the industry and enterprises involved make their specific development strategies according to the country's actual conditions and maximally contribute to the development of the industry or the concerned enterprise. In this way, the domestic biomass energy industry can be guided to the sound and orderly development beneficial to the whole country.

\subsection{Policy Support and the Biomass Energy Market}

For many years, the related laws and regulations, government's fiscal, foreign trade and regulatory polices of the USA and EU help to promote the sound operation of the biomass power generation industry, and play an important role in forming the industry chain for the production, consumption and distribution of biomass power. 


\subsection{Sound Market of Energy Industry}

The biomass energy development cannot be sustainable if solely depending on the incentive and protection by policy without the role of market being fully played. The sole dependence on the favorable policy deprives the development rigor and even leads to the abnormal development. Based on the sound market of energy industry, considering the features of the agricultural and forestry areas and the environmental requirements, the USA and EU make full use of the market and pricing mechanism in the financing, production and sales and cooperation long the industry chain, promote the diversification business operation of the biomass power generators, and help to build a positive competition pattern.

\subsection{How to Guarantee the Raw Materials Supply}

Raw materials supply of biomass power generation plays a fundamental role in the industry. The USA, EU and Brazil, based on the domestic biomass energy development strategy, considering the regional characteristics of biomass resources, the regional industry development, and interests of raw materials suppliers, have built the industrial chain - supply chain mode for cooperation and development, to ensure the supply of raw materials for biomass. The industrial chain - supply chain mode provides a solid material foundation for the sustainable development of the biomass power generation industry.

\subsection{Technology Research and Development}

Japan, the USA and EU highly value the innovation in biomass energy technology. Not only abundant government funds and corresponding supporting policies are directly granted in the technology development, cutting-edge research and development, industrialization, commercialization, and promotion of the applied processes in biomass energy are also encouraged through various channels such as enterprise associations and strategic business alliance.

\subsection{International Cooperation and Competitiveness of the Industry}

For countries with abundant resources yet underdeveloped biomass energy industry, it is far from ideal to reject introduction and importation of the advanced technology but insist on conducting independent research and development on their own. Independent R\&D often leads to inefficient utilization of resources, high cost in development, shortage of funds, as well as limitations to the expansion of the industry scale. In this sense, some African and Asian countries have broken their system obstacles and positively cooperated internationally, which not only promoted the sound development of the industry in the countries, but also enhanced the competitiveness of the industry.

\section{Measures for the Orderly Development of Biomass Power Generation Industry in China}

\subsection{Investigation and Assessment of the Biomass Resources}

In-depth investigations of the biomass substance should be carried out to grasp a thorough understanding of the present conditions and potential of all kinds of resources including the main properties of the main biomass substance, appropriate marginal land resources, distribution in regions, amount and distribution of livestock and poultry breeding, storage of garbage and industrial waste. An effective technical assessment method and index system can be established, and the utilization means of the resources for biomass power generation can be reasonably and rationally made.

\subsection{Development Mechanism for Biomass Power Generation Industry}

As research on the policy theory for the development mechanism of the biomass energy industry is insufficient in China, more efforts should be made in research on the theory regarding fiscal supporting policies and market mechanism. Second, the market mechanism should be cultivated with an appropriate pricing system gradually perfected, including granting green power permits and carbon trade to improve the profitability of the biomass power project. For the existing problems of the pricing system for biomass power, based on the floating pricing system, emphasis should be laid on making full use of the market competition mechanism to encourage the power generators to upgrade technology and reduce cost and use the subsidy policy of the government more effectively. The effective use of government subsidy and incentives for biomass power electricity price incentives is encouraged to attract more investment. We can adopt the green taxation mode as developed countries have to share the cost of biomass substance. For instance, green taxes can be levied on the pollutant-producing enterprises for subsidies for biomass energy enterprises.

\subsection{Good Environment for Investment}

Dependence on the sole means of the government fiscal input and investment constraints the sustainable development in the biomass energy industry. Instead, an efficiency and credit evaluation system can be 
constructed, and more projects can be financed with the aid of bank loans, domestic and foreign security markets and risk investment funds, international credits or by means of BOT. A good investment environment should be developed so that private investors will be encouraged to invest in this sector.

\subsection{Well-coordinated and Unified Regulation Institution}

First, a coordination and management commission should be established to be responsible for regulation and supervision of the biomass energy industry to replace the existing joint management pattern of all the related government departments. Second, coordination and specialization among the related sectors and departments should be strengthened. Under the unified organization and management of the commission, a coordinating mechanism can be build among all the participants such as the NDRC, the MOA and China Electricity Regulatory Commission with a clear division of responsibilities and strengthened cooperation spirit to jointly study major issues of biomass energy power generation and propose policy suggestions. Guidance and supervision should be intensified for the local biomass power development so that more efficient and favorable policies can be made in terms of coordination and planning, investigation of resources, technology promotion and fiscal support and industry support.

\section{References}

Cannell, M. G. R. (2003). Carbon sequestration and biomass offset: theoretical, potential and achievable capacities globally, in Europe and the UK. Biomass and Bioenergy, 24(2), 97-116.

Gong, J. P. (2010, June). National forestry biomass energy development planning (2011-2010). Retrieved from http://swzny.forestry.gov.cn

Henniges, O. (2006). Bioenergy in Europe: Experiences and Prospects, Bioenergy and Agriculture. Promises and Challenges, (12).

Liang, Z. R. (2010, February 1). 2010: start 41 garbage power "chain sets". Retrieved from http://epaper.21cbh.com

Meng, F. S. (2008). Biomass gasification power generation problem research. China National Conditions and Strength, (9).

Moreira, J. R. (2006). Brazil's experience with Bioenergy, Bioenergy and Agriculture. Promises and Challenges, (12).

Shi, L. S. (2004). Analysis on the current situation of Chinese and renewable energy source development plan. Renewable energy source, (5), 1-4.

Shi, Y. C. (2005). The rising biomass energy. Life World, (4), 16.

Xin, X. (2005). Biomass - a new bright spot in future global energy. Energy saving and environmental protection, (10), 15-17.

Zhang, W. D., Liu, S. Q., \& He, C. Y. (1996). Biomass potential and energy conversion. Natural resource, (4). 20-24.

Zhu, Y. Q., Zhu, L. Z. \& Zhao, H. Y. (2010). New energy and distributed power generation technology. Beijing, Peking University Press. 